\title{
A INTERNALIZAÇÃO DOS DIREITOS HUMANOS E FUNDAMENTAIS À LUZ DO CONCEITO MODERNO DE DEMOCRACIA: UM DIÁLOGO ENTRE CUBA, PORTUGAL E BRASIL
}

\section{THE INTERNALIZATION OF HUMAN AND FUNDAMENTAL RIGHTS IN THE LIGHT OF THE MODERN CONCEPT OF DEMOCRACY: A DIALOGUE BETWEEN CUBA, PORTUGAL AND BRAZIL}

\author{
Pablo Jiménez Serrano ${ }^{1}$ \\ Regina Célia Martinez ${ }^{2}$
}

\section{Resumo}

O presente artigo tem por objetivo o estudo da relação necessária entre os Direitos Humanos e Fundamentais e o conceito moderno de democracia. Por meio de uma leitura comparada, caracteriza-se a tutela desses importantes direitos nos sistemas jurídicos cubano, português e brasileiro. Apresenta-se o conceito de internacionalização como uma forma de dimensionar os direitos fundamentais, em face de sua real garantia e concretização, procurando, assim, diminuir as diferenças de sentido e aplicação. Conclui-se que, a pesar do seu reconhecimento formal, os Direitos Humanos e fundamentais estão longe de serem efetivados. Propõe-se, finalmente, o conceito de democracia como uma premissa fundamental para a concretização dos direitos em estudo.

Palavras-chaves: Direitos Humanos. Direitos Fundamentais. Internacionalização. Democracia.

\begin{abstract}
The purpose of this article is to study the necessary relationship between Human and Fundamental Rights and the modern concept of democracy. Through a comparative reading, it is characterized the protection of these important rights in the Cuban, portuguese and Brazilian legal systems. The concept of internationalization is presented as a way of assessing fundamental rights, given their real guarantee and concretization, in order to reduce differences of meaning and application. It is concluded that, despite their formal recognition, human and fundamental rights are far from being fulfilled. Finally, the concept of democracy is proposed as a fundamental premise for the realization of the rights under study.
\end{abstract}

Keywords: Human Rights. Fundamental rights. Internationalization. Democracy.

\footnotetext{
${ }^{1}$ Doutor em Direito pela Faculdade de Direito da Universidade do Oriente, Cuba. Professor e pesquisador do Programa de Mestrado em Direito do Centro Universitário Salesiano de São Paulo- UNISAL. Professor e pesquisador do Centro Universitário de Volta Redonda, UniFOA. Professor e pesquisador do Centro Universitário de Barra Mansa, UBM. E-mail: contato@jurismestre.com.br

${ }^{2}$ Doutora pela Pontifícia Universidade Católica de São Paulo. Professora e Pesquisadora do Programa de Mestrado em Direito da Sociedade da Informação das Faculdades Metropolitanas Unidas São Paulo Laureate. Professora da Escola Paulista da Magistratura de São Paulo (EPM). E-mail: reginamarar@uol.com.br
} 


\section{INTRODUÇÃO}

No presente artigo privilegia-se o estudo da correlação existente entre os Direitos Humanos e Fundamentais e as democracias latino-americanas. O estudo tem como principal objetivo desenvolver uma pesquisa comparada entre os sistemas de direitos fundamentais cubano, português e brasileiro em face da sua correlação com o conceito democracia.

Os estudos jurídicos devidamente fundamentados, isto é, desenvolvidos por meio de métodos adequados, valorizam as doutrinas: conceitos, interpretações, generalizações e princípios jurídicos que são próprios dos diferentes sistemas de direito e sociedades. Assim sendo, o Direito comparado desempenha um papel fundamental para o desenvolvimento da ciência do Direito e, especificamente, dos Direitos Humanos e Fundamentais, pois oferece os meios com os quais se confrontam as ordens (ou ordenamentos), instituições, regras, teorias e doutrinas jurídicas. (SERRANO, 2015)

Do ponto de vista teórico-metodológico e, aos efeitos da presente pesquisa, significamos os Direitos Humanos como: o conjunto de direitos que objetivam a promoção da dignidade do ser humano e, como consequência, constitui-se em premissas para a realização da cidadania e da democracia.

Contudo, o estudo tem como hipótese principal que os direitos humanos abrangem direitos aceitos por todas as culturas: direitos necessários para a convivência social e para a realização da democracia.

Desta forma, os direitos fundamentais e os direitos humanos alicerçam a sociedade democrática por serem direitos essenciais em cada comunidade nacional.

Todavia, importa considerar a Vida: vida digna, vida em sociedade como a essência e razão desses direitos e o cerne fundamental da democracia. Eis que, o respeito e garantia dos direitos fundamentais e humanos é condição a primordial de toda sociedade civilizada. Daí, que a exclusão, o preconceito e o egoísmo classista tornam-se indicadores precisos da falta de democracia.

Um sistema verdadeiramente democrático é aquele que legitima mudanças democraticamente apontadas pelo povo e que têm como valor básico os princípios universais de direitos humanos.

Nesse sentido a democracia seria uma condição, um princípio primário para a realização do ser humano que almeja construir, efetivamente, seu futuro numa determinada comunidade 
solidária. Tal construção implica, necessariamente, que os direitos fundamentais e humanos caminhem para uma concepção universal.

\section{INTERNACIONALIZAÇÃO DOS DIREITOS HUMANOS}

A expressão "direitos humanos" é concebida na forma mais abrangente possível do seu significado: um ideal (ou dever ser) que nos orienta na busca da vida, da paz, da justiça e a realização do ser humano. Diz-se de "uma via, um método a ser desenvolvido por toda a humanidade em direção à realização da dignidade humana, fim de todos os governos e povos". (JAYME, 2005, p.1)

A expressão "direitos humanos" é uma forma abreviada de mencionar os direitos fundamentais da pessoa humana. Esses direitos são considerados fundamentais porque sem eles a pessoa humana não consegue existir ou não é capaz de se desenvolver e de participar plenamente da vida. Todos os seres humanos devem ter asseguradas, desde o nascimento, as condições mínimas necessárias para se tornarem úteis à humanidade, como também devem ter a possibilidade de receber os benefícios que a vida em sociedade pode proporcionar. Para entendermos com facilidade o que significam direitos humanos, basta dizer que tais direitos correspondem a necessidades essenciais da pessoa humana. Trata-se daquelas necessidades que são iguais para todos os seres humanos e que devem ser atendidas para que a pessoa possa viver com a dignidade que deve ser assegurada a todas as pessoas. Assim, por exemplo, a vida é um direito humano fundamental, porque se ela a pessoa não existe. Então a preservação da vida é uma necessidade de todas as pessoas humanas. Outras necessidades são também fundamentais, como a alimentação, a saúde, a moradia, a educação, e tantas outras coisas. (DALLARI, 1998, p. 7)

Destarte, os direitos humanos podem ser definidos como um conjunto de direitos básicos e necessários para o desenvolvimento do ser humano, isto é, de uma vida digna com base na liberdade. Identificam-se, assim, os direitos humanos com:

a plenitude do direito à vida, sob o aspecto físico e moral; daí, consagrarem a dignidade da pessoa humana como seu fim. A idéia de direitos humanos, como realização da dignidade humana, deve ser compreendida de forma dinâmica, por representarem eles, os direitos humanos, patamares mínimos para uma existência digna. Todavia, os valores neles consagrados, tais como liberdade, igualdade, democracia, bem-estar, felicidade, são cláusulas abertas e, portanto, inexauríveis. Assim, respeitar os direitos humanos significa conferir condições mínimas, necessárias para o indivíduo desenvolver seus potenciais com o máximo de liberdade possível. (JAYME, 2005, p. 2) 
O Direito Internacional dos Direitos Humanos, apresenta um caráter específico e especial, que os distingue do Direito Internacional público em geral. Enquanto este busca tradicionalmente disciplinar relações de reciprocidade e equilíbrio entre Estados, por meio de negociações e concessões recíprocas que visam ao interesses dos próprios Estados pactuantes, o Direito Internacional dos Direitos Humanos objetiva garantir o exercício dos direitos da pessoa humana. Contudo, privilegia-se uma análise interdisciplinar, já que se localiza justamente na interação entre o Direito Constitucional e o Direito Internacional dos Direito Humanos. A interdisciplinaridade aponta para uma resultante: o chamado Direito Constitucional Internacional, integração que assume um caráter especial quando esses dois campos buscam resguardar um mesmo valor, o valor da primazia da pessoa humana. (PIOVESAN, 2010, p. 15-17)

As primeiras manifestações de direitos humanos se remontam ao ideal de homem abstrato do jusnaturalismo antigo. Sabe-se que, somente, a partir do século XIII consideram-se formuladas as bases para uma doutrina posterior acerca dos direitos naturais. Ora, como bem ensina Ingo Wolfgang Sarlet (2007, p. 36), a consideração de que a denominação "direitos humanos" pode ser equiparada aos "direitos naturais" não nos parece correta, uma vez que a própria positivação em normas de direito internacional já revela, de forma incontestável, a dimensão histórica e relativa dos direitos humanos, que assim se desprenderam, ao menos em parte da idéia de um direito natural. Todavia, não devemos esquecer que, na sua vertente histórica, os direitos humanos (internacionais) e fundamentais (constitucionais) radicam no reconhecimento, pelo direito positivo, de uma série de direitos naturais do homem, que, neste sentido, assumem uma dimensão pré-estatal e, para alguns, até mesmo supra-estatal. Cuida-se, assim, dos direitos humanos, considerados como tais aqueles outorgados a todos os homens pela sua mera condição humana, mas, neste caso, de direitos não-positivados. Cumpre assim traçar uma distinção, ainda que de cunho didático, entre as expressões: "direitos do homem" (no sentido de direitos naturais não, ou ainda não positivados), "direitos humanos" (positivados na esfera do direito internacional) e "direitos fundamentais" (reconhecidos ou outorgados e protegidos pelo direito constitucional interno de cada Estado).

Foi, contudo, por meio da passagem do feudalismo para o capitalismo que se possibilitou a defesa de um ideal de homem fraterno e livre que acelerou o anseio por uma sociedade justa. Contudo, por meio dos conhecidos princípios: "liberdade", "igualdade" e "fraternidade" criaram-se a base para uma formação econômica e social democrática. Consequentemente viram-se na dignidade e na liberdade do ser humano as premissas para a realização do direito e da democracia. 
As lutas de classe aceleraram as mudanças no campo do Direito Internacional, surgindo, assim, a "Declaração de Virgínia", de 12 de junho de 1776, a "Declaração dos Direitos do Homem e do Cidadão" da Assembléia Nacional francesa, de 1789. Desta forma, criaram-se as condições para declarações do século XVIII, que acentuaram o confronto sociopolítico.

A reafirmação internacional dos direitos humanos deu-se, pela transformação e reformulação dos direitos fundamentais. Daí a conhecida "geração de direitos" tratada sucessivamente pela doutrina nacional e estrangeira.

Assim, por exemplo, falou-se em uma primeira geração dos direitos humanos que abrange os direitos á liberdade e a autonomia do indivíduo, direitos que teriam como gênese as revoluções liberais do século XVIII (na Europa e Estados Unidos). Os direitos da Declaração de Virgínia e da Declaração francesa de 1889 são, nesse sentido, direitos de primeira geração, fundamentados no contratualismo de inspiração individualista. São vistos como direitos inerentes ao indivíduo, uma vez que precedem o contrato social.

Uma segunda geração exigiria do Estado um papel ativo para a realização dos direitos de primeira geração. Tais direitos, também elencados na Constituição mexicana de 1917, na Constituição alemã de Weimar de 1919 e, no Direito Internacional, o Tratado de Versailles, possibilitaram a Organização Internacional do Trabalho, por meio da qual se reconheceram importantes direitos dos trabalhadores. Diz-se que os direitos de segunda geração se configuram a partir da complementação histórica dos direitos individuais, pelas reivindicações dos despossuídos, as exigências para participar do bem-estar social, sendo o fundamento dos direitos do indivíduo em relação ao coletivo (direito ao trabalho, à saúde, à educação etc.). Como é claro, o reconhecimento destes direitos depende da posição que adote o estado, principalmente, com os serviços públicos.

Já os direitos de terceira geração incluiriam, posteriormente, o direito ao desenvolvimento, o direito à paz, o direito à autodeterminação e, em especial, o direito a um meio-ambiente equilibrado. São os direitos de titularidade coletiva, tais como: o direito à autodeterminação dos povos e outros direitos, derivados das relações internacionais, são conseqüências de conflitos nascidos das relações entre as comunidades e, também, resultado de toda geração que aqui se explica. Hoje, por exemplo, num nível mais geral, pensa-se nos direitos mais universais da humanidade, considerando-os, também, como direitos humanos:

a) o direito a um meio ambiente, pelo qual toda pessoa tem necessidade de viver num meio sadio e a contar com os serviços públicos básicos; 
b) o direito à educação, como direito à capacitação de todas as pessoas, para participar efetivamente de uma sociedade democrática, favorecendo a tolerância, a amizade entre todas as nações e todos os grupos sociais, étnicos ou religiosos e promover as atividades em favor da manutenção da paz;

c) o direito à saúde, como gozo do mais alto nível de bem-estar físico, mental e social;

d) o direito aos benefícios da cultura, do progresso científico e tecnológico, da proteção dos interesses morais e materiais que a eles correspondam, em virtude de produções científicas, literárias e artísticas;

e) o direito à constituição e proteção da família, como elemento fundamental da sociedade;

f) o direito à proteção das crianças, pelo qual toda criança tem o direito de crescer no amparo da família, da sociedade e do Estado;

g) o direito à proteção dos idosos e dos "deficientes";

h) o direito à integração econômica dos Estados, segundo as áreas e regiões geográficas e afins.

Todavia, outros novos direitos são elencados dentro do conjunto de direitos humanos, a saber, o direito ao desenvolvimento, reivindicado pelos países subdesenvolvidos nas negociações, o direito à paz, pleiteado nas discussões sobre desarmamento; o direito ao meio ambiente argüido no debate ecológico; e o reconhecimento dos fundos oceânicos como patrimônio comum da humanidade, a ser administrado por uma autoridade internacional e em benefício da humanidade em geral. (LAFER, 1991, p. 131)

\section{DIREITOS HUMANOS E DIREITOS FUNDAMENTAIS: EQUIPARAÇÃO DOS CONCEITOS}

A passagem do Estado Liberal para o Estado de Bem-estar social estimulou o surgimento de um pensamento, isto é, de uma nova interpretação dos direitos sociais, ora expressos na forma de direitos fundamentais ou de direitos humanos. Devido a tal equiparação os construtos "direitos fundamentais" e "direitos humanos" foram considerados e usados, indistintamente, como construções linguísticas idênticas ou similares nos diferentes discursos políticos e obras científicas e doutrinárias.

Contudo, é mister distinguir ambas as denominações e, neste sentido, Ingo Wolfgang Sarlet (2007, p. 33-34), destaca que vale a opção pela denominação "direitos fundamentais", o que, no entanto, não torna dispensável uma justificação, ainda que sumária, deste ponto de 
vista, no mínimo pela circunstância de que, tanto na doutrina, quanto no direito positivo (constitucional ou internacional), são largamente utilizadas (e até com maior intensidade), outras expressões, tais como "direito do homem", "direitos subjetivos públicos", "liberdades públicas", "direitos individuais", "liberdades fundamentais", "direitos humanos fundamentais", apenas para referir algumas das mais importantes. A exemplo do que acorre em outros textos constitucionais, continua o citado autor, há que reconhecer que também a Constituição de 1988, em que pesem os avanços alcançados, continua a se caracterizar por uma diversidade semântica ao se referir aos direitos fundamentais. Assim, por exemplo, usam-se na Constituição expressões como: a) direitos humanos (art. 4으, inc. 11); b) direitos e garantias fundamentais (epígrafe do Título II, e art. 5o); c) direitos e liberdades constitucionais (art. 5, inc. LXX) e d) direitos e garantias individuais (art. 60).

Certamente, a constatação de que os direitos fundamentais revelam uma dupla perspectiva, na medida em que podem, em princípio, ser considerados tanto como direitos subjetivos individuais, quanto elementos objetivos fundamentais da comunidade, constitui, sem sobra de dúvidas, uma das mais relevantes formulações do direito constitucional contemporâneo, de modo especial no âmbito da dogmática dos direitos fundamentais. Trata-se de uma importante função atribuída aos direito fundamentais e desenvolvida com base na existência de um dever geral de efetivação atribuído ao Estado, por sua vez agregado à perspectiva objetiva dos direitos fundamentais, diz com o reconhecimento de deveres de proteção do Estado, no sentido de que a este incumbe zelar, inclusive preventivamente, pela proteção dos direitos fundamentais dos indivíduos no somente contra os poderes públicos, mas também contra agressões provindas de particulares e até mesmo de outros Estados. Esta incumbência, por sua vez, desemboca na obrigação de o Estado adotar medidas positivas da mais diversa natureza (por exemplo, por meio de proibições, autorizações, medidas legislativas de natureza penal etc.), com o objetivo de proteger de forma efetiva o exercício dos direitos fundamentais. (SARLET, 2007, p. 174-175)

Desta forma, pese sejam ambas as denominações "direitos humanos" e "direitos fundamentais" comumente utilizadas como sinônimas, a explicação corriqueira e, diga-se de passagem, procedente para a distinção é de que a denominação "direitos fundamentais" se aplica para aqueles direitos do ser humano reconhecidos e positivados na esfera do direito constitucional positivo de determinado Estado (SARLET, 2007, p. 35-36).

A necessidade da exigência dos direitos fundamentais e humanos se reafirma, pois eles independem de da positivação normativa, eles existem independentemente de sua positivação 
em leis e tratados e alberga o direito a vida: à sobrevivência. Vê-se, aí, incluído o conceito de cidadania e democracia como formando os alicerces de tais direitos.

\section{CORRELAÇÃO ENTRE OS DIREITOS HUMANOS E FUNDAMENTAIS E AS DEMOCRACIAS}

Há, de fato, uma correlação específica entre os Direitos Humanos e Fundamentais e a democracia. Podemos considerar que sem democracia, os Direitos Humanos e Fundamentais são impossíveis de serem concretizados.

Vê-se que, a pesar do seu reconhecimento formal, os Direitos Humanos e fundamentais estão longe de serem efetivados na maioria dos países ibero-americanos. Verifica-se que a democracia constitui uma condição para a concretização dos direitos em estudo.

\section{Tutela dos Direitos Fundamentais em Cuba}

O projeto revolucionário sempre esteve condenado ao fracasso e isto se deve a diversas razões, a saber, primeira, a centralização das decisões numa única pessoa, segunda, o pensamento individualista e egoísta proposto pela elite governante, terceiro, a falta de planejamento eficiente e objetivo para o desenvolvimento socioeconômico do país, quarto, a idealização proposital de um projeto socioeconômico que somente conduz a um desequilíbrio moral.

A centralização das decisões numa única pessoa (no líder máximo da revolução cubana) condenou ao fracasso o desenvolvimento socioeconômico nacional. Naturalmente sabe-se impossível e irracional que uma única pessoa possa decidir, com êxito, o destino de um país. É interessante relembrar que durante 58 anos a política, o direito, a economia e a sociedade em conjunto estiveram nas mãos de um único indivíduo. Isto se traduziu num evidente autoritarismo, ou seja, numa hierarquização das decisões, que originou a negação de outras tantas possibilidades e formas de resolver os problemas cubanos.

A ordem econômica cubana resultou ser uma quimera. Confundiram-se as leis propostas pelo socialismo e pelo comunismo clássico, erro que tornaria irrealizável a justiça social. A respeito da ordem econômica e da justiça social, veja-se o artigo 14 da Constituição da República de Cuba:

Na República de Cuba rege o sistema de economia baseado na propriedade socialista de todo o povo sobre os meios fundamentais de produção e na supressão da exploração do homem pelo homem. 
Também rege o princípio de distribuição socialista "de cada um segundo seu trabalho". A lei estabelece as regras que garantem o efetivo cumprimento deste princípio, (tradução minha).

Como quer que seja, o desequilíbrio socioeconômico e jurídico vê-se justificado pela negação da democracia, pela censura, pelo culto à personalidade e pelos métodos usados para estimular o ódio, a desinformação e o medo infundado já enraizado no meio social etc. A questão da cidadania na ordem nacional cubana pode ser discutida com base na análise da realização ou da não-realização dos direitos fundamentais prescritos na Constituição da República de Cuba.

Artigo 9: O Estado:

a) realiza a vontade do povo trabalhador e oficializa os esforços da nação na construção do socialismo;

$[\ldots]$

- garante a liberdade e a dignidade plena do homem, o gozo dos seus direitos, o exercício e o cumprimento dos seus deveres e o desenvolvimento integral de sua personalidade.

b) como poder do povo, a serviço do próprio povo, garante:

- que não haja homem ou mulher em condições de trabalhar, que não tenha oportunidade de obter emprego com o qual possa contribuir para os fins da sociedade e para satisfazer suas próprias necessidades;

- que não haja pessoa incapacitada para o trabalho que não tenha meios decorosos de subsistência;

- que não haja enfermo que não tenha assistência médica;

- que não haja criança que não tenha escola, alimentação e vestimenta;

- que não haja pessoa que não tenha acesso ao estudo, à cultura e ao esporte;

c) trabalha para conseguir que não haja família que não tenha uma morada confortável, (tradução minha).

Fique claro que, um discurso sobre cidadania deve considerar o acesso concreto aos direitos fundamentais da pessoa humana. Por isto, como veremos mais adiante, a exclusão social é uma forma de negação da cidadania. É preciso destacar que por alguma razão o conceito cidadania não é usado nos discursos da elite do governo cubano. Ele aparece, de preferência, na fala dos dissidentes e dos intelectuais, sendo objeto do debate familiar ou de grupos, geralmente quando se pensa na ausência de liberdades e na impossibilidade de reivindicar direitos.

\section{Há exclusão social em Cuba?}

Ora, vamos examinar a questão da "exclusão social", mais ou menos deste modo: a exclusão social compreende a supressão de direitos, ou melhor, a negação, a violação ou privação de direitos. Trata-se de um fenômeno que diz respeito ao não acesso a determinados bens e serviços basilares para o desenvolvimento: crescimento material e espiritual do ser humano. 
A exclusão social em Cuba tem suas origens na desinformação. Ela é inconstitucional e contrária ao consagrado no já citado artigo 41 da Constituição cubana: "Todos os cidadãos gozam de iguais direitos e estão sujeitos a iguais deveres", (tradução minha).

Mas, após cinco décadas de desigualdade social e de pobreza podemos afirmar que os cubanos foram e, ainda, são excluídos da ordem econômica, política e jurídica nacional. Acontece que, por um lado, o consumo e o desfrute dos bens são próprios da classe dirigente: dos favorecidos, dos comprometidos (ex. dirigentes do partido, da União de Jovens Comunistas, dos sindicados, e das demais organizações sociais, os membros da segurança, ministros e familiares e amigos de todos aqueles que ocupam cargos públicos), por outro lado, a produção (o esforço, o sacrifício) sobra para a classe trabalhadora a qual é minimizada e controlada por aqueles que se escudam no comando constitucional previsto no artigo 16 da Constituição da República de Cuba:

Artigo 16: O Estado organiza, dirige e controla a atividade econômica nacional conforme um plano que garante o desenvolvimento programado do país, para fortalecer o sistema socialista, satisfazer cada vez mais as necessidades materiais e culturais da sociedade e dos cidadãos, promover o desenvolvimento da pessoa humana e a sua dignidade, o avanço e a segurança do país. Na elaboração e execução dos programas de produção e desenvolvimento participam ativa e conscientemente os trabalhadores de todos os ramos da economia e das demais esferas da vida social. (Tradução minha)

Na verdade, são as instituições estatais, orientadas pela pessoa do líder máximo, que controlam a atividade econômica nacional conforme um plano previamente elaborado pela elite que ostenta o poder. Assim, de forma aparente, pretende-se garantir o desenvolvimento programado do país para, supostamente, fortalecer o sistema socialista, satisfazer cada vez mais as necessidades materiais e culturais da sociedade e dos cidadãos, promover o desenvolvimento da pessoa humana e sua dignidade, o avanço e a segurança do país.

Atualmente, novas desigualdades tornam-se evidentes e estão associadas ao acesso à tecnologia que garante a informação. Assim, por exemplo, o governo cubano bloqueia e nega o acesso da informação, ora através da Internet. O cubano não tem direito a adquirir uma linha de telefone e só tem acesso à informação autorizada pelo governo veiculada pela impressa escrita, pela rádio e pela tv.

Ainda que os problemas econômicos e a inversão de valores na sociedade cubana incomodem o governo, não existe interesse real em transformar esse quadro. A própria experiência nos ajuda a afirmar que os agentes do governo, quando tomam decisões relativas ao poder e às liberdades, o fazem desconsiderando o bem-estar social. Assim, o governo 
cubano nega constantemente a Constituição. O que eu quero dizer é que o estabelecido na Constituição cubana hoje é letra morta. Veja-se, por exemplo, o prescrito no artigo 43 da Constituição cubana:

Artigo 43: O Estado consagra o direito conquistado pela Revolução de (que) cidadãos, sem distinção de raça, cor da pele, sexo, crenças religiosas origem nacional e qualquer outra lesiva à dignidade humana:

$[\ldots]$

- tenham acesso segundo méritos e capacidades, a todos os cargos e empregos do Estado, da Administração Pública e da produção e prestação de serviços;

- ascendam a todas as hierarquias das forças armadas revolucionárias e da segurança e ordem interior segundo méritos e capacidades;

- percebam salário igual por trabalho igual;

- desfrutem do ensino em todas as instituições docentes do país, desde a escola primária até as universidades, que são as mesmas para todos;

- recebam assistência em todas as instituições de saúde;

- tenham domicílio em qualquer setor, zona ou bairro das cidades e se alojem em qualquer hotel;

- sejam atendidos em todos os restaurantes e demais estabelecimentos de serviço público;

- usem, sem separação, os transportes marítimos, ferroviários, aéreos e automotores;

- desfrutem dos mesmos balneários, praias, parques, círculos sociais e demais centros de cultura, esporte, recreação e descanso. (Tradução minha).

Em verdade nem todo cubano tem acesso a cargos e empregos do Estado, da Administração Pública e da produção e prestação de serviços. Quem professar crenças e ideias diferentes ou contrárias às do governo está excluído de ocupar cargos públicos e tampouco são aceitos nas Forças Armadas Revolucionárias nem na segurança e ordem interior. A escolha ou seleção para estudar nas instituições docentes do país é feita sob investigação, pela qual os indicadores: crença religiosa, participação das atividades programadas pelas organizações políticas e sociais (UJC, CDR etc.), etc. sempre foram decisivos.

Nem todos têm acesso aos melhores hospitais do país. Os que moram no interior são proibidos de fixar residência na capital (Havana). Os cubanos são proibidos de se alojarem em hotéis, reservados unicamente para o turismo. Hoje, somente aqueles cubanos que, por alguma razão, têm dólares ou euros, isto é, recebem dinheiro do exterior, enviado por familiares, têm direito a entrar nas instalações turísticas. Mas, quantos são? A mesma limitação existe para entrar em restaurantes e demais estabelecimentos, para outros serviços públicos como o transporte (ferroviário, aéreo e automotor), balneários e praias etc. Os homens de minha terra natal, os cubanos que sofrem tais privações, sabem perfeitamente o difícil que é comprar passagem para viajar dentro da Ilha. Para outro país, nem pesar. 
Examinemos outro exemplo: ainda hoje, os profissionais e intelectuais cubanos vivem numa situação desconfortável. A falta de liberdade de expressão e de escolha faz com que o profissional, perante a possibilidade de ser contratado por empresas e instituições estrangeiras, aceite salários desproporcionais com a atividade a ser desempenhada dentro da llha ou em país estrangeiro. Assim, as necessidades desses profissionais e o risco de não poder sair da llha os obriga a aceitar descontos de até $70 \%$ ou mais dos seus salários. Eu, por exemplo, numa dada época estava obrigado a enviar essa porcentagem para Cuba, caso contrário teria que regressar.

Em Cuba, conforme dados publicados pela organização Anistia Internacional ${ }^{3}$, as liberdades de expressão, associação e de movimento continuaram submetidas a graves restrições em 2007. A Anistia Internacional relembra no texto que pelo menos 62 "presos de consciência" ${ }^{4}$ seguem detidos "por suas opiniões ou atividades políticas não violentas", e que houve intimidação e reclusão para dissidentes, jornalistas independentes e ativistas de direitos humanos. A Anistia Internacional complementa que todos os meios de comunicação impressos e audiovisuais seguem sob controle estatal e que não foram renovados os vistos de vários correspondentes estrangeiros que já publicaram reportagens sobre o país. O relatório anual denuncia que várias pessoas foram condenadas pelo crime de "periculosidade social", aplicado "de forma quase exclusiva" a dissidentes políticos, jornalistas e aqueles que criticam o governo.

É preciso observar que modernamente convencionou-se chamar "preso de consciência" ao preso político cubano. É o cidadão que defende opiniões contrárias ao regime. Crime severamente sancionado pelo governo. Assim, penaliza-se o indivíduo por pensar e manifestar uma ideia contrária às ideias do governo. Invalida-se a "consciência" que é atributo do ser humano.

Entender a realidade cubana é entender a estratégia do governo que consiste em castrar (cortar pela raiz) a consciência individual: restringir, frustrar, reprimir e neutralizar por meio do castigo ou pelo medo ou quaisquer sentimentos ou tendências desfavoráveis ao regime, evitando-se, assim, focos de lideranças e de organização contra-revolucionária na sociedade. Esse temor perpétuo por parte do regime cubano é a causa da perseguição da dissidência: daqueles que se manifestam contrários à maneira ditatorial de resolver os problemas cubanos.

\section{Tutela dos Direitos Fundamentais em Portugal}

\footnotetext{
${ }^{3}$ Disponivel em: http://www.estadao.com.br/internacional/not_int179587,0.htm. Data de acesso: 20 de junho de 2008. [Anistia condena 60 anos de fracasso em direitos humanos].

${ }^{4}$ Preso político: modalidade que tem como único motivo manifestar ideias contrárias ao regime.
} 
Ao nível da tutela, garantia ou ação nos direitos fundamentais em Portugal (que, para efeitos práticos, tomaremos como sinônimas da forma prática protetiva e procedimental/processual) desde logo se colocam problemas teóricos e terminológicos. Não é, desde logo, indiferente, considerar que exista uma autotutela dos direitos fundamentais ou que as situações que nesta se compreendem sejam apenas consideradas como meios extra-judiciais de proteção.

Falar em autotutela remete-nos pelo menos para a sugestão de um direito próprio do cidadão, que o exerce em certas circunstâncias e sob certas formas não incompatíveis com a "delegação de poderes" que, com um ou sem explícito contrato social, transferiu para a comunidade política, neste caso o Estado - através da representação política, que, aliás, tem aqui em São Paulo um grande ator, José Pedro Galvão de Sousa. Falar em meios não jurisdicionais dilui esta questão num problema organizatório/procedimental, apartando o que é contencioso do que o não é.

Meios como o direito de resistência (art. 21) e de petição (art. 52 Lei n. 43/90, de 10 de agosto) afiguram-se-nos cabalmente dentro do âmbito da autotutela, existindo mesmo que a constituição os ignorasse e até se a lei os proibisse. Infelizmente, nos desgraçados tempos que correm em Portugal há muita gente a invocar o direito de resistência como uma espécie de direito à desobediência, outros quiçá mesmo como direito à insurreição. A tal ponto nos levam as medidas trituradoras que ainda ontem subiam os impostos em mais quase $40 \%$. Não é para $40 \%$, é mais $40 \%$. Contudo, até por este fato, é importante saber bem até onde vão estes direitos de autotutela.

Já, porém, as garantias procedimentais e face à Administração Pública são meios não jurisdicionais mas que fundam a sua etiologia no direito positivo, na sua inventiva e condicionalidade próprias, e numa como que colaboração entre o particular e o Estado.

A par das vias de autotutela e não jurisdicionais, há a dimensão protetiva contenciosa. Não existindo em Portugal recurso direto dos particulares para o Tribunal Constitucional (do gênero do recurso de amparo, ou a panóplia de remédios constitucionais que existem no Brasil - já nem falamos do Habeas Pinho), há, porém, outras formas de proteção (além, evidentemente, de se poder suscitar em qualquer processo de qualquer tribunal competente a questão da inconstitucionalidade ou da legalidade).

O recurso contencioso contra lesões aos direitos ou interesses legalmente protegidos está garantido pelo art. 268, n. 4, incluindo, além de outros (porque a enumeração é 
expressamente exemplificativa), a ação declarativa sobre tais direitos e interesses, a impugnação de atos lesivos, a injunção para a prática de atos administrativos legalmente devidos, e a adoção de providências cautelares.

A Justiça Administrativa coopera assim, naturalmente, na tutela constitucional, podendo falar-se de um princípio da plenitude da garantia jurisdicional administrativa, pelo qual nenhuma ofensa aos direitos ou interesses legalmente protegidos the pode ser alheia. Mesmo que ela decorra, por exemplo, de uma norma administrativa com eficácia externa (art. 268, n. 5). Cremos que esta fórmula foi cunhada por causa da velha polêmica doutrinal portuguesa sobre o que venha a ser um ato administrativo (que para a escola de Lisboa, segundo a escola de Coimbra, algo pleonasticamente, deveria ser "definitivo e executório").

É, evidentemente, possível suscitar recurso para o Tribunal Constitucional com base em inconstitucionalidade ou ilegalidade de normas surgida nos tribunais (art. 280).

À disposição dos particulares estão ainda dois tipos de ação: a de responsabilidade do Estado, para reparação de danos emergentes de ações ou omissões (lícitas ou ilícitas, atos jurídicos ou ações materiais) de entidades públicas no exercício das suas funções e por causa desse exercício (arts. 22ㅇ․ e 27ㅇ․ e Estatuto dos Tribunais Administrativos e Fiscais, art. 51ํ., n1h); e a ação popular ( Lei no. 83/95).

Esta última compõe-se, em boa verdade, de uma dimensão meramente procedimental (direito procedimental de participação popular), garantindo audição de cidadãos e grupos em matérias da última ou penúltima geração (ou dimensão) de direitos (ambiente, urbanismo, consumo, etc.), assim tutelando interesses difusos, e de uma dimensão propriamente contenciosa ou jurisdicional. Revestindo formas diversas (administrativa ou civil, procedimental ou processual propriamente dita), a ação popular lato sensu visa, sobretudo, a tutela desses bens e interesses cuja difusibilidade de assunção pessoal justifica um procedimento mais atento ao fenômeno de massas.

Os direitos econômicos, sociais e culturais, tendo especificidades, não podem, em rigor e na essência das coisas, ser considerados adventícios ou parentes pobres dos demais direitos. Nunca será demais recordar que não pode ser ferido o seu núcleo essencial, nem operar-se retrocesso de proteção sem razões muito ponderosas, nem, a seu propósito, violar-se a aplicação do princípio da igualdade. Como foi recentemente o caso no confisco de dois salários por ano aos funcionários públicos, e apenas a eles, conforme declarado no Acórdão do Tribunal 
Constitucional Acórdão no. 353/12 . Mas note-se: ao contrário do que o Governo interpretou, a desigualdade não reside no tratamento de favor dado aos trabalhadores privados, mas aos titulares de outro tipo de rendimentos. Numa atitude inédita, viria o Presidente do Tribunal explicar: "A crítica da ligeireza do Tribunal Constitucional parte de um postulado errado. O acórdão não se baseia na comparação entre titulares de rendimento de origem público ou privada - baseia-se na diferença entre titulares de rendimento. Portanto, quando se chama a atenção para a comparação entre o público e o privado, está-se a fazer uma leitura redutora do acórdão - este fala de titulares de rendimento, que não só públicos ou privados. Porque, antes de mais, esses são só do trabalho e há outros que estão também em causa: os rendimentos do capital”, explicou o Conselheiro Prof. Doutor Rui Moura Ramos em declarações à Antena $1 .{ }^{6}$

Este caso é significativo no plano da grande dificuldade portuguesa em atacar normas inconstitucionais, nomeadamente de tipo orçamental. Perante o silêncio do Presidente da República e dos demais órgãos com legitimidade para suscitar a apreciação preventiva (art. 278․ 1 e 4 da CRP), seria em sede de fiscalização abstrata (art. 281, 2) que ela seria requerida, também no silêncio de todos os outros, por um décimo dos deputados à Assembléia da República (alínea f), o que obrigou a uma aproximação pontual de deputados de diferentes partidos, nem sempre muito convergentes nos últimos tempos, pelo menos.

Cremos que as brutais medidas anunciadas ontem poderão ter o mesmo caminho. Mas, dada a recente renovação de membros do Tribunal Constitucional, e dada a culpabilização que ocorreu no último Acórdão, como vimos, é uma incógnita saber-se qual será a decisão, desta feita.

\footnotetext{
${ }^{5}$ Citando parcialmente: "O Tribunal verificou que esta medida se traduzia numa imposição de um sacrifício adicional que não tinha equivalente para a generalidade dos outros cidadãos que auferem rendimentos provenientes de outras fontes, tendo concluído que a diferença de tratamento era de tal modo acentuada e significativa que as razões de eficácia na prossecução do objetivo de redução do défice público que fundamentavam tal opção não tinham uma valia suficiente para a justificar.

Por isso entendeu que esse diferente tratamento a quem aufere remunerações e pensões por verbas públicas ultrapassava os limites da proibição do excesso em termos de igualdade proporcional. Apesar da Constituição não poder ficar alheia à realidade econômica e financeira, sobretudo em situações de graves dificuldades, ela possui uma específica autonomia normativa que impede que os objetivos económicosfinanceiros prevaleçam, sem qualquer limite, sobre parâmetros como o da igualdade, que a Constituição defende e deve fazer cumprir. Por estas razões, o Tribunal concluiu que a dimensão da desigualdade de tratamento que resultava das normas sob fiscalização, ao revelar-se manifestamente desproporcionada perante as razões que a fundamentavam, se traduzia numa violação do princípio da igualdade, consagrado no art. 13, da Constituição, pelo que declarou inconstitucionais as normas constantes dos artigos 21‥ e 25․, da Lei no. 64-B/2011, de 30 de dezembro ( Lei do Orçamento de Estado para 2012). ${ }^{6}$ Informação disponível em: http://rr.sapo.pt/informacao_detalhe.aspx?did=69936. Data de acesso 15 de setembro de 2016.
} 
Além da declaração de inconstitucionalidade por ação há também a inconstitucionalidade por omissão. Não apenas a inconstitucionalidade por omissão é sanção de violação dos direitos sociais, podendo, nestes termos, haver inconstitucionalidades por ação neste âmbito, com as consequências normais destes casos a deverem de aí ser extraídas.

Não deixa de ser curioso que o primeiro caso (e dos raros) de inconstitucionalidade por omissão seja o que declarou como tal a ausência de subsídio de desemprego para...os professores universitários. Que, porém, tiveram que esperar muito até que tal viesse a ser reconhecido.

Mas de novo teremos certamente motivo para inconstitucionalidades por ação, já que o Conselho de Ética para as Ciências da Vida (CNECV) acaba de, num parecer, caucionar todos os cortes na saúde a velhos ou incuráveis (fala-se concretamente de cancerosos e aidéticos), por explicitamente apelar a uma lógica economicista e de "racionamento". O presidente daquele órgão declarou, para se justificar: "Será que mais dois meses de vida, independentemente dessa qualidade de vida, justifica uma terapêutica de 50 mil, 100 mil ou 200 mil euros?

A proteção dos direitos fundamentais não se circunscreve, evidentemente, aos limites das nossas fronteiras. Com o aprofundamento da União Européia e de formas internacionais de integração, sinais dos tempos de globalização, cada vez mais as jurisdições de recurso ou as instâncias de petição se multiplicam. As instituições e os mecanismos protetivos da União Européia merecem todo um estudo à parte, claro.

Outras formas de proteção poderão ainda recordar-se. À luz da Convenção Européia dos Direitos do Homem, o cidadão português sentindo-se lesado nos seus direitos fundamentais pode peticionar a Comissão Européia dos Direitos do Homem, a qual, por ação desta ou doutro Estado, pode levar a um processo no Tribunal Europeu, o qual já condenou o Estado português em alguns casos.

Particularmente preocupante nos parece o recurso para instâncias europeias em matéria de liberdade de expressão, que, a crer na tese de José Preto, Estado contra Direito, estaria a sofrer algumas limitações, ou, pelos menos, graves incompreensões, mesmo ao nível judicial.

Há também, mas no âmbito das Nações Unidas, um procedimento não jurisdicional, mas de influência, algo semelhante ao da provedoria da justiça ao nível nacional: a possibilidade de exposição e queixa por parte de um cidadão para o Comitê dos Direitos do Homem respectivo, que, comunicando-as aos Estados, os fará analisar o problema com a força do seu 
prestígio. E finalmente, depois das respostas dos Estados, o Comitê concluirá, em relatório a apresentar à Assembléia Geral da ONU.

Além disso, o Tribunal Penal Internacional tutela já algumas graves lesões de direitos fundamentais que configurem crime no âmbito da tipificação legal do âmbito da sua competência. Curiosamente, o terrorismo não parece ser aí tipificado. A não criminalização da pirataria, por outro lado, tem levado a que certos estados, como a Holanda, tenham desenterrado já leis do século XVII, e outros soltem os piratas.

Mas sobre piratas recordo sempre um sketch humorístico que nos remete para outra pirataria, de que somos diuturnamente vítimas. Nessa série televisiva, aparecem em uma nau piratas desventurados com outros piratas:

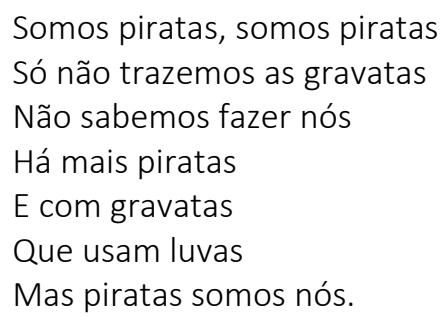

Esclareça-se que em Portugal chamamos propinas às mensalidades normais e legais nas universidades, e chamamos às propinas (luvas). Decerto porque houve tempo em que se fazia parte da nossa propina, dar luvas aos funcionários da Universidade. Eu ainda tive que, irrepreensível e legalmente embora, pagar "doces de ovos " quando foi a cerimônia solene do meu doutoramento.

\section{Tutela dos Direitos Fundamentais em Brasil}

Em Brasil, a pesar do reconhecimento e da tutela legal dos Direitos Humanos e Fundamentais, existe um quadro de "exclusão social" que acaba prejudicando a sua concretização, fala-se, assim, da exclusão como a forma de negação de importantes direitos sociais: educação, saúde, moradia, transporte, lazer, assistência social e, mais especificamente, à assistência jurídica.

Em verdade, os direitos fundamentais deveriam ser considerados direitos de aplicabilidade imediata, assim prescrito no próprio $\S 10$ do art. 5 da Constituição Federal (as normas definidoras dos direitos e garantias fundamentais têm aplicação imediata).

Desta forma, determina a vigente Constituição Federal que se dê aplicabilidade imediata ao exercício desses direitos previstos, cujo rol não é exemplificativo, a teor do 20 do art. 5 da Constituição Federal de 1988 (os direitos e garantias expressos nesta Constituição não 
excluem outros decorrentes do regime e dos princípios por ela adotados, ou dos tratados internacionais em que a República Federativa do Brasil seja parte). Conclui-se que são direitos que independem de normas criadoras de instituições ou de sistemas que facilitem a aquisição da casa própria. (SOUZA, 2008. p. 134)

Ora, a negação desses direitos tem uma extraordinária repercussão de caráter sóciojurídica, pois atinge a "dignidade" e a "justiça social": são conceitos decisivos para a integração das normas constitucionais e infraconstitucionais a cada caso concreto, procurando-se com isso a melhor forma de garantir a harmonia social (paz social) finalidade também reconhecida no preâmbulo constitucional e almejada por todos.

Vê-se que a exclusão social brasileira, se assenta na corrupção, aqui considerada como um vício moral que afeta todos direito e se manifesta como uma forma de negar a justiça social e a democracia. Daí que a inclusão social tem a democracia como meio e a justiça social como fim.

Observa-se, pois, que a inclusão social, assim como a garantias dos direitos fundamentais e humanos fortaleceram o conceito de democracia, assim como a democracia se tornou alicerce desses direitos. Resta, contudo, aprofundarmos no tema da moralidade pública para, no cenário político-administrativo concretizar ainda mais tais direitos.

Fala-se, assim, da importância das boas escolhas das lideranças (agentes públicos) para possibilitar a concretização dos direitos fundamentais e humanos por meio do Executivo, do Legislativo e do judiciário.

Liga-se, desta forma, o discurso acerca da democracia à moralidade política e administrativa em termos de subordinar os interesses individuais e partidários aos interesses sociais objetivando uma sociedade livre, justa e solidária.

\section{A DEMOCRACIA COMO PREMISSA PARA A CONCRETIZAÇÃO DOS DIREITOS HUMANOS E FUNDAMENTAIS}

O conceito de "democracia" representa a mais alta expressão da civilização humana. Eis que, o ideal da democracia, em teoria, objetiva garantir a liberdade, a dignidade e a participação popular. O vocábulo "democracia" deriva do grego "démokratía, de dêmos 'povo' + kratía, isto é, "força, poder". É um conceito, por meio do qual se designa o povo decidindo seu futuro e exercendo o poder. 
Vê-se, assim, que a questão da democracia encontra-se profundamente enraizada na proteção dos direitos fundamentais da pessoa humana, na medida em que não existirá democracia sem cidadania e sem acesso efetivo a direitos fundamentais da pessoa humana. Daí, que a inclusão social e a garantia dos direitos fundamentais e humanos estejam, de fato, ligadas à democracia.

Nesse sentido, qualquer definição do conceito "democracia" acaba por colocar os direitos humanos e fundamentais na tônica do cidadão e da sociedade (do povo). Ora, importar distinguir democracia participativa e a democracia representativa com o objetivo de caracterizar a concretude, isto é, a realização social do conceito.

Vemos, assim, que um autêntico ideário democrático é aquele que possibilita a solidariedade e a justiça social, que somente se possibilitam na medida em que se respeitam os direitos fundamentais e humanos.

Coloca-se, assim, o povo como meio de legitimar o Estado, povo-ativo (participante das decisões políticas); povo como instância global de atribuição de legitimidade, povo-ícone; e o povo como destinatário das decisões e atuações públicas. (KELSEN, 2000, p. 36-40)

Na verdade, o conceito de povo é usado para legitimar do Estado, sua democracia. Assim, conferimos nas constituições contemporâneas e mesmo na Constituição da República Federativa do Brasil:

Art.10 - A República Federativa do Brasil formada pela união indissolúvel dos Estados e Municípios e do Distrito Federal; constituí-se em Estado Democrático de Direito e tem como fundamentos:

I - a soberania;

II - a cidadania;

III - a dignidade da pessoa humana;

IV - os valores sociais do trabalho e da livre iniciativa;

$\checkmark$ - o pluralismo político.

Parágrafo Único - Todo o poder emana do povo, que o exerce por meio de representantes eleitos ou diretamente nos termos desta Constituição. (Grifo nosso)

Vê-se que os chamados representantes, aqueles ao quais se outorgam poderes de representação, no que tange às estruturas políticas e governamentais vigentes, elegem-se do povo e são denominados povo-ativo, o titular dos direitos políticos.

A respeito desse tema Friedrich Müller (2003, p. 127) ensina os diferentes modos de se significar o povo, de acordo com a aplicação do direito e da tentativa de efetivação do Estado Democrático. Vemos, assim, que o conceito de democracia pressupõe a inclusão social e, consequentemente a efetivação dos direitos fundamentais e os direitos humanos. 
Nesse sentido, se afirma que uma democracia verdadeiramente participativa é aquela onde a participação é necessária e concreta e onde o povo se converte em ator principal e não mais como mero coadjuvante, como aquele que está apto de fato a reivindicar sua posição proeminente em uma sociedade livre, solidária e justa (BONAVIDES, 2003, p. 281-296).

Modernamente, e contrariamente ao que acontecia nas décadas dos 60 e 70, a democracia passou a ganhar forças e, conforme nos ensina Bonavides (2003, p. 157) o Estado social, tornou-se humanizador do poder, jurídico nos fundamentos sociais da liberdade, democrático na essência de seus valores, padece, de último, ameaça letal à conservação das respectivas bases e conquistas. Esmaecê-lo e depois destruí-lo é parte programática das fórmulas neoliberais propagadas em nome da globalização e da economia de mercado, bem como da queda de fronteiras ao capital migratório, cuja expansão e circulação sem freio, numa velocidade imprevisível, contribui irremissivelmente para decretar e perpetuar a dependência dos sistemas nacionais, indefesos, e desprotegidos, sistemas que demoram nas esferas do Terceiro Mundo".

Em suma, como ensina Moreira Neto (1992): a democracia, enquanto conjunto de valores, é um modo de vida; enquanto instituição, conforma um regime político e, enquanto práxis, é uma técnica social para compor interesses diversos. Somente pelo exercício permanente do diálogo, da conciliação e do consenso, pilastras da legitimidade, um povo aprende a cultivar a democracia como estilo de vida e a mantê-la como regime político.

\section{CONCLUSÃO}

Os direitos humanos constituem um conjunto de direitos indissolúvel por meio dos quais se objetiva garantir a vida e a dignidade de todo ser humano.

Embora tais direitos existam formalmente, a realidade mundial indica uma dissociação ou falta de correspondência dos mesmos com a realidade existencial de muitos países onde é visível a injustiça social.

Contudo, é imprescindível falar em tecnicismos, mas também em efetividade da ordem jurídica, procurando, desta forma, inibir os problemas que notoriamente atingem a sociedade como um todo, a saber, o desemprego, a miséria, a fome, dificuldades de acesso a terra, à saúde, à educação etc.

No mundo contemporâneo, subsistem situações sociais, políticas e econômicas que contribuem para tornar os homens supérfluos, por isso, a crise dos direitos humanos continua 
na ordem do dia (LAFER, 1991, p. 118). O conhecimento da Teoria da Geração desses direitos nos brinda a possibilidade de compreender o porquê da existência de enfoques diferentes sobre a matéria. Portanto, "o fato de explicar os direitos humanos como parte integrante da lógica individualista significa conceber a liberdade como faculdade de autodeterminação de todo ser humano" (Ibid., p. 120).

Nas realidades concretas ibero-americana e, especificamente, a cubana, a portuguesa e a brasileira, eventuais defesas à proteção dos direitos do homem colocam em confronto alguns direitos, a saber: o direito à liberdade e o direito à propriedade versus a integridade física, a segurança e outros direitos sociais (ou coletivos): educação, saúde, moradia, lazer, emprego etc.

Destarte, ao se advogar pelo reconhecimento dos direitos fundamentais do ser humano, com freqüência deixa-se de privilegiar determinados direitos sociais. Privilegiam-se determinados privilégios econômicos de classes ou grupos e se subordinam a eles alguns direitos sociais básicos: educação, emprego, segurança social, acesso à informação, à cultura etc.

Importa, nesse sentido, analisar o modo pelo que a Constituição brasileira incorpora os tratados internacionais de proteção dos direitos humano, atribuindo-Ihe um estatus hierárquico diferenciado. Embora estes tratados sejam elaborados com o fim de importar em obrigações aos Estados que os ratificam, os seus verdadeiros benefícios são os indivíduos que estão sob a jurisdição do Estado. Destarte, a incorporação efetiva das normas desses tratados no plano nacional é de crucial importância para que os seus propósitos sejam alcançados. (PIOVESAN, 2010, p. 4).

Hodiernamente, a situação vigorante na maioria dos países parece justificar a necessidade de rever os conceitos acerca dos direitos fundamentais e dos direitos humanos, com o intuito de evoluir para uma sociedade mais justa, onde o Estado e as organizações nãogovernamentais e a sociedade em conjunto, atuem procurando fins comuns.

Os direitos humanos devem ser interpretados e aplicados, de forma a alcançar a proteção dos direitos do homem inserido na sociedade. O abandono da idéia do homem em abstrato é premissa fundamental para a formação de um critério razoável. Assim, a denominação direitos humanos rompe a clássica divisão do direito em público e privado, para se identificar como aqueles direitos mais gerais, isto é, relativos à humanidade. Por isso mesmo, sua expressão tem de significar a atenção ao ser humano, ao homem, pois sem o homem, não há direitos humanos. 
Há de se privilegiar e efetivar a preservação da saúde e do bem-estar coletivo, logrados por meio de projetos sociais, relativos à alimentação, à moradia e à assistência médica. Todavia, deve-se trabalhar para objetivar uma educação digna, por meio da qual se capacite ao ser humano que assim será mais útil à sociedade: o acesso à cultura, aos benefícios da tecnologia e dos resultados dos avanços científicos em geral.

Em suma, é mister garantir o direito a uma vida plena que envolva a proteção da integridade física; o direito à liberdade e à igualdade perante o próprio direito e a democracia.

\section{REFERÊNCIAS}

BOBBIO, Norberto. A Era dos Direitos. Trad. Carlos Nelson Coutinho. Rio de Janeiro: Campus, 1992. Terra, 1992.

O Futuro da Democracia: Uma defesa das regras do jogo. 5. ed. Rio de Janeiro: Paz e Liberalismo e Democracia. São Paulo: Brasiliense, 1998.

BONAVIDES, Paulo. Teoria constitucional da democracia participativa: por um direito constitucional de luta e resistência, por uma nova hermenêutica, por uma repolitização da legitimidade. 2. ed. São Paulo: Malheiros, 2003.

DALLARI, Dalmo de Abreu. Direitos Humanos e Cidadania. São Paulo: Moderna, 1998.

JAYME, Fernando G. Direitos humanos e sua efetivação pela corte interamericana de direitos humanos. Belo Horizonte: Del Rey, 2005.

KELSEN, Hans. A Democracia. 2. ed. São Paulo: Martins Fontes, 2000.

LAFER, Celso. A reconstrução dos direitos humanos - um diálogo com o pensamento de Hannah Arendt. São Paulo: Companhia das Letras, 1991.

MOREIRA NETO, Diogo de Figueiredo. Direito da participação política: fundamentos e técnicas constitucionais da democracia. Rio de Janeiro: Renovar, 1992.

MÜLLER, Friedrich. Quem é o povo: A questão fundamental da democracia. São Paulo: Max Limonad, 1998.

PIOVESAN, Flávia. Direitos humanos e o direito constitucional internacional. 11. ed. São Paulo: Saraiva, 2010.

SANTOS, Boaventura de Sousa. Democratizar a Democracia: os caminhos da democracia participativa. Rio de Janeiro: Civilização brasileira, 2002.

SARLET, Ingo Wolfgang. A eficácia dos direitos fundamentais. 3. ed. ver. atual. e ampl. Porto Alegre: Livraria do Advogado, 2007. 
SERRANO, Pablo Jiménez. Curso de direito comparado. Rio de Janeiro: Jurismestre (www.loja.jurismestre.com.br), 2015a.

Memórias de um cubano. Rio de Janeiro: Jurismestre (www.loja.jurismestre.com.br), 2015b.

Doutrina dos Direitos Humanos. Rio de Janeiro: Jurismestre (www.loja.jurismestre.com.br), 2016.

SOUZA, Sérgio Iglesias Nunes de. Direito à Moradia e de Habitação. 2. ed. São Paulo: Rt, 2008.

Trabalho enviado em 13 de junho de 2017.

Aceito em 28 de julho de 2017. 